Article

\title{
Is Hybridization a Source of Adaptive Venom Variation in Rattlesnakes? A Test, Using a Crotalus scutulatus $\times$ viridis Hybrid Zone in Southwestern New Mexico
}

\author{
Giulia Zancolli ${ }^{1}$, Timothy G. Baker ${ }^{1}$, Axel Barlow ${ }^{1,2}$, Rebecca K. Bradley ${ }^{1}$, Juan J. Calvete ${ }^{3}$, \\ Kimberley C. Carter ${ }^{1}$, Kaylah de Jager ${ }^{1}$, John Benjamin Owens ${ }^{1}$, Jenny Forrester Price ${ }^{1}$, \\ Libia Sanz $^{3}$, Amy Scholes-Higham ${ }^{1}$, Liam Shier ${ }^{1}$, Liam Wood ${ }^{1}$, Catharine E. Wüster ${ }^{1}$ \\ and Wolfgang Wüster 1,4,* \\ 1 Molecular Ecology and Fisheries Genetics Lab, School of Biological Sciences, Bangor University, \\ Bangor LL57 2UW, UK; giulia.zancolli@gmail.com (G.Z.); bsu057@bangor.ac.uk (T.G.B.); \\ axel.barlow.ab@gmail.com (A.B.); bsu069@bangor.ac.uk (R.K.B.); kimc@live.co.uk (K.C.C.); \\ bsue65@bangor.ac.uk (K.D.J.); bsu052@bangor.ac.uk (J.B.O.); jennyp@live.co.uk (J.F.P.); \\ amy.scholes.higham@gmail.com (A.S.-H.); bsu049@bangor.ac.uk (L.S.); woodlc08@hotmail.com (L.W.); \\ c.wuster@me.com (C.E.W.) \\ 2 Evolutionary and Adaptive Genomics Group, Institute for Biochemistry and Biology, University of Potsdam, \\ Karl-Liebknecht-Str. 24-25, Haus 29, 14476 Potsdam (Golm), Germany \\ 3 Venomics and Structural Proteomics Laboratory, Instituto de Biomedicina de Valencia, Consejo Superior de \\ Investigaciones Científicas (CSIC), Jaume Roig 11, 46010 Valencia, Spain; jcalvete@ibv.csic.es (J.J.C.); \\ libia.sanz@ibv.csic.es (L.S.) \\ 4 Chiricahua Desert Museum, P.O. Box 376, Rodeo, NM 88056, USA \\ * Correspondence: w.wuster@bangor.ac.uk
}

Academic Editor: Bryan Grieg Fry

Received: 6 May 2016; Accepted: 9 June 2016; Published: 16 June 2016

\begin{abstract}
Venomous snakes often display extensive variation in venom composition both between and within species. However, the mechanisms underlying the distribution of different toxins and venom types among populations and taxa remain insufficiently known. Rattlesnakes (Crotalus, Sistrurus) display extreme inter- and intraspecific variation in venom composition, centered particularly on the presence or absence of presynaptically neurotoxic phospholipases $A_{2}$ such as Mojave toxin (MTX). Interspecific hybridization has been invoked as a mechanism to explain the distribution of these toxins across rattlesnakes, with the implicit assumption that they are adaptively advantageous. Here, we test the potential of adaptive hybridization as a mechanism for venom evolution by assessing the distribution of genes encoding the acidic and basic subunits of Mojave toxin across a hybrid zone between MTX-positive Crotalus scutulatus and MTX-negative C. viridis in southwestern New Mexico, USA. Analyses of morphology, mitochondrial and single copy-nuclear genes document extensive admixture within a narrow hybrid zone. The genes encoding the two MTX subunits are strictly linked, and found in most hybrids and backcrossed individuals, but not in C. viridis away from the hybrid zone. Presence of the genes is invariably associated with presence of the corresponding toxin in the venom. We conclude that introgression of highly lethal neurotoxins through hybridization is not necessarily favored by natural selection in rattlesnakes, and that even extensive hybridization may not lead to introgression of these genes into another species.
\end{abstract}

Keywords: adaptation; Crotalus; evolution; hybridization; introgression; Mojave toxin; molecular evolution; venom 


\section{Introduction}

Variation in venom composition is a ubiquitous phenomenon in venomous snakes at all taxonomic levels, from temporal variation within individuals to higher levels. [1,2]. The often extensive compositional variation between conspecific populations or between closely related species has been of particular interest, partly due to its medical consequences [3-5] and partly due to its potential as a model system for understanding adaptive evolution at the molecular level (e.g., [6-8]): many species display extreme intraspecific geographic variation in venom composition, and this variation may bear little relationship to population genetic structure or organismal phylogeny [9,10]. Natural selection for optimization of venom to the diet of snakes has been identified as a likely key driver of venom evolution in several groups [9,11-13]. However, these examples consist primarily of snakes with extreme dietary variation and/or disjunct distributions (e.g., Calloselasma rhodostoma), or groups of well-differentiated species (e.g., Micrurus, Echis), and the forces underlying venom variation in other cases remain poorly understood [10,14,15]. Moreover, the genetic mechanisms underlying variation in snake venom composition, and the distribution of individual toxins among populations and species, remain largely unknown.

Rattlesnakes (genera Crotalus and Sistrurus) constitute an excellent group of model organisms for the study of venom variation, as they display extensive inter- and intraspecific variation in venom composition [16]. An underlying theme in Crotalus appears to be the presence of alternative and often largely mutually exclusive envenoming strategies: type I venoms [16] contain large amounts of snake venom metalloproteinases (SVMPs), whereas type II venoms contain a high concentration of presynaptically neurotoxic, heterodimeric PLA 2 toxins such as crotoxin and Mojave toxin (MTX) $[17,18]$, and are typically considerably more lethal in the mouse model than their type I counterparts.

Remarkably, the distribution of these different strategies among rattlesnakes shows little congruence with phylogeny or even species limits. Both strategies can be found across the full phylogenetic breadth of rattlesnakes. Species showing intraspecific variation, with different conspecific snakes secreting either type I and type II venoms [5,14,19-24], can be found in all major rattlesnake clades [16]. This intraspecific variation can be ontogenetic, such as in C. simus, where the venom changes from type II to type I during ontogeny [25,26], or geographic, in species such as C. scutulatus and C. horridus, where both venom types occur in different parts of their distributional range $[14,21,27]$. In at least some cases, such as C. scutulatus, this variation appears to be related to the presence or absence of the genes encoding these toxins rather than gene expression [22,28-30].

Mapping these apparently homologous toxins onto the phylogeny of rattlesnakes would require remarkable numbers of gene loss events, or, even less plausibly, astonishingly numerous instances of convergent evolution. An alternative explanation for these patterns, which bypasses this difficulty, is adaptive hybridization. Hybridization has long been flagged as a potential source of adaptive variation and innovations [31,32]. Extensive studies of hybrid zones between closely related species or differentiated conspecific populations have demonstrated that selectively advantageous genes are able to cross hybrid zones and spread into the other species, provided they are not linked to deleterious alleles at other loci [33-35]. This applies even with slight reductions in hybrid fitness, which cause these zones to act as sinks for selectively neutral alleles [33,36].

The hypothesis of a hybridogenic origin of the startling parallel patterns of intraspecific venom variation in several rattlesnakes holds considerable intuitive appeal: by effectively providing a shortcut for gene transfer between the branches of rattlesnake phylogeny, introgressive hybridization would explain geographic variation in the presence of particular gene orthologs in multiple unrelated species more parsimoniously than any hypothesis based solely on phylogenetic relationships. Glenn and Straight [37] suggested that the presence of MTX-like toxins in some individuals of Crotalus viridis (Prairie rattlesnake) from southwestern New Mexico was due to hybridization with nearby populations of type II venom C. scutulatus. Aird et al. [38] noted the resemblance between the venoms of C. atrox and type I venom C. scutulatus, and suggested that the type I venoms of some C. scutulatus populations may be due to past hybridization between the two species. More recently, the presence of neurotoxic 
$\mathrm{PLA}_{2}$ toxins in some populations of $C$. horridus has been variously attributed to past hybridization with Crotalus scutulatus [39] and Sisturus catenatus [30]. Similar arguments have been made to explain the presence of neurotoxic PLA 2 toxins in some European vipers [40,41]. However, none of these studies provided any independent evidence of interspecific hybridization having taken place. Moreover, despite this interest in hybridization as a possible mechanism for venom variation, we are not aware of any published study rigorously examining venom composition across a well characterized hybrid zone in any venomous animal.

Interspecific hybridization, potentially as a result of anthropogenic disturbance, has also been invoked in the popular literature to explain a claimed increase in the clinical severity of rattlesnake bites in the USA [42]. The evidence for this hypothesized increase was robustly deconstructed by Hayes and Mackessy [43]. However, the intriguing question remains whether occasional hybridization events could result in the rapid spread of novel, selectively advantageous toxin genes through the gene pool of a different species. Given their radical effect on venom function and lethality, one could hypothesize that highly lethal toxins such as MTX might be especially prone to this form of introgression and subsequent selective sweeps.

It is an implicit assumption of any hypothesis of hybridogenic introgression of venom toxin genes that the introgressing genes confer a selective advantage to the receiving gene pool [33,35]. By the same token, any true hybrid zone between rattlesnake species with different venom compositions would thus provide a test of the hypothesis that particular toxins could be highly selectively advantageous and could spread rapidly across species limits after hybridization. Since individual variation in venom composition can lead to differential venom effectiveness against different prey species [44], and thus to potential differences in individual fitness, this scenario seems potentially feasible.

Although numerous individual hybrids between different species and even genera of rattlesnakes have been documented [45-50], the frequency and importance of hybridization have been disputed [51]. The present study was prompted by the discovery of multiple specimens phenotypically intermediate between the Mohave rattlesnake (Crotalus scutulatus) and the Prairie rattlesnake (C. viridis) in a contact zone along the eastern slope of the Peloncillo Mountains, Hidalgo County, New Mexico, where the two species are largely parapatric [52]. This region corresponds approximately to the location from which Glenn and Straight [37] reported MTX-secreting specimens of Crotalus viridis, which they interpreted as evidence of hybridization with neighboring populations of type II venom C. scutulatus.

A third large rattlesnake species, the western diamondback (C. atrox), occurs sympatrically with both species in Arizona and New Mexico, and also across the hybrid zone. Hybridization between C. scutulatus and C. atrox has been suspected of shaping venom composition in the former [37]. Moreover, a few individuals in the putative $C$. scutulatus $\times$ viridis hybrid zone were visually intermediate between C. scutulatus and C. atrox rather than C. scutulatus and C. viridis. We therefore included all three large, sympatric rattlesnake species from the area in this assessment of hybridization and its effects on venom composition.

Here, we use this apparent hybrid zone to test the hypothesis that highly lethal neurotoxic PLA 2 toxins are likely to introgress into the gene pool of species lacking them. We analyze morphological data, mitochondrial DNA and single-copy nuclear gene sequences to test for evidence of hybridization between $C$. scutulatus and C. viridis or C. atrox. We then test for the presence of the genes encoding the acidic and basic subunits of the Mojave toxin using a PCR-based assay and sequencing, and relate the presence or absence of the toxin to the hybrid status of the snakes. Finally, we verified the presence of MTX in the venom by reverse-phase high performance liquid chromatography (RP-HPLC) to establish a link between hybrid status, toxin genotype and venom phenotype. 


\section{Results}

\subsection{Morphology}

Principal coordinates analysis of nine characters of head scalation and tail coloration revealed clearly distinct clusters representing the three species C. atrox, C. scutulatus and C. viridis, with a number of phenotypically intermediate specimens originating from the C. scutulatus-C. viridis contact zone in Hidalgo County, New Mexico. The analysis revealed both specimens intermediate between C. scutulatus and C. atrox, and between C. scutulatus and C. viridis, but not between C. atrox and C. viridis (Figure 1).

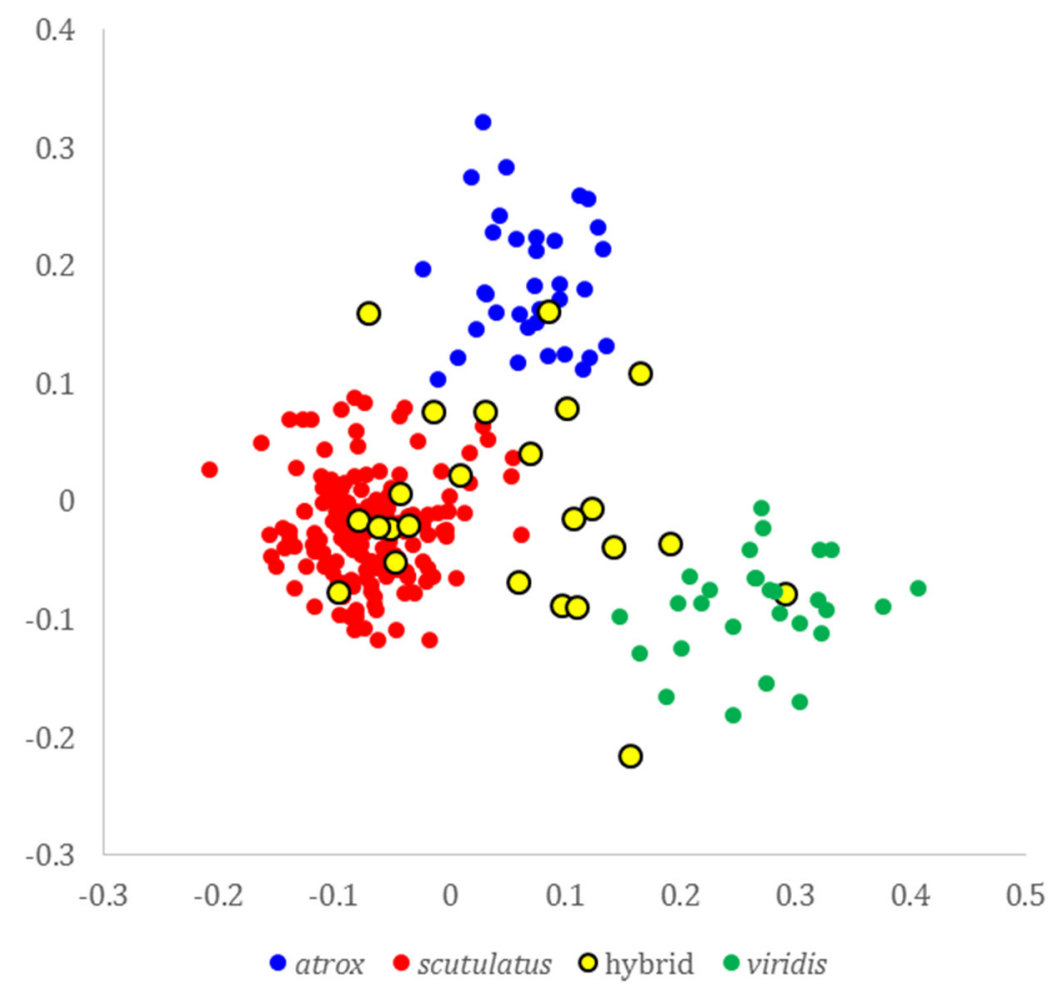

Figure 1. Ordination of specimens of C. scutulatus, C. atrox, C. viridis and putative hybrids along the first two axes of a principal components analysis of nine morphological characters. All specimens from the eastern slope of the Peloncillo Mountains in southwestern New Mexico are labeled as hybrids irrespective of morphological or genetic profile. The first and second principal components represent $41.5 \%$ and $23.7 \%$ of the total variance, respectively.

\subsection{Molecular Evidence of Hybridization}

We obtained sequences of the mitochondrial NADH subunit 4 (ND4) gene and four single-copy nuclear genes (NT3, R35, SELT, ETS) from 156 specimens (40 C. atrox, 56 C. scutulatus, 34 C. viridis and 26 specimens from the putative $C$. scutulatus $\times$ viridis hybrid zone). Information on our sequence alignments is shown in Table 1. A neighbor-joining tree obtained from the mitochondrial ND4 sequences (Figure 2) grouped all specimens into three clusters corresponding to the three species under study, with $99 \%$ bootstrap support for the monophyly of the haplotypes of each species. The vast majority of specimens from the putative hybrid zone carried C. scutulatus haplotypes, and a few C. viridis haplotypes. No putative hybrid haplotypes clustered as C. atrox. Mitochondrial sequences and phased haplotype sequences of all nuclear genes are available under GenBank accession numbers KX256288-KX257025. 
Table 1. Sequence characteristics of ND4 and single copy nuclear gene sequence alignments used in this study.

\begin{tabular}{cccccc}
\hline Sequence parameters & ND4 & NT3 & R35 & SELT & ETS \\
\hline Length (bp) & 635 & 538 & 531 & 346 & 653 \\
\# haplotypes & 57 & 39 & 18 & 20 & 26 \\
\# variable positions & 139 & 31 & 15 & 17 & 29 \\
\hline
\end{tabular}

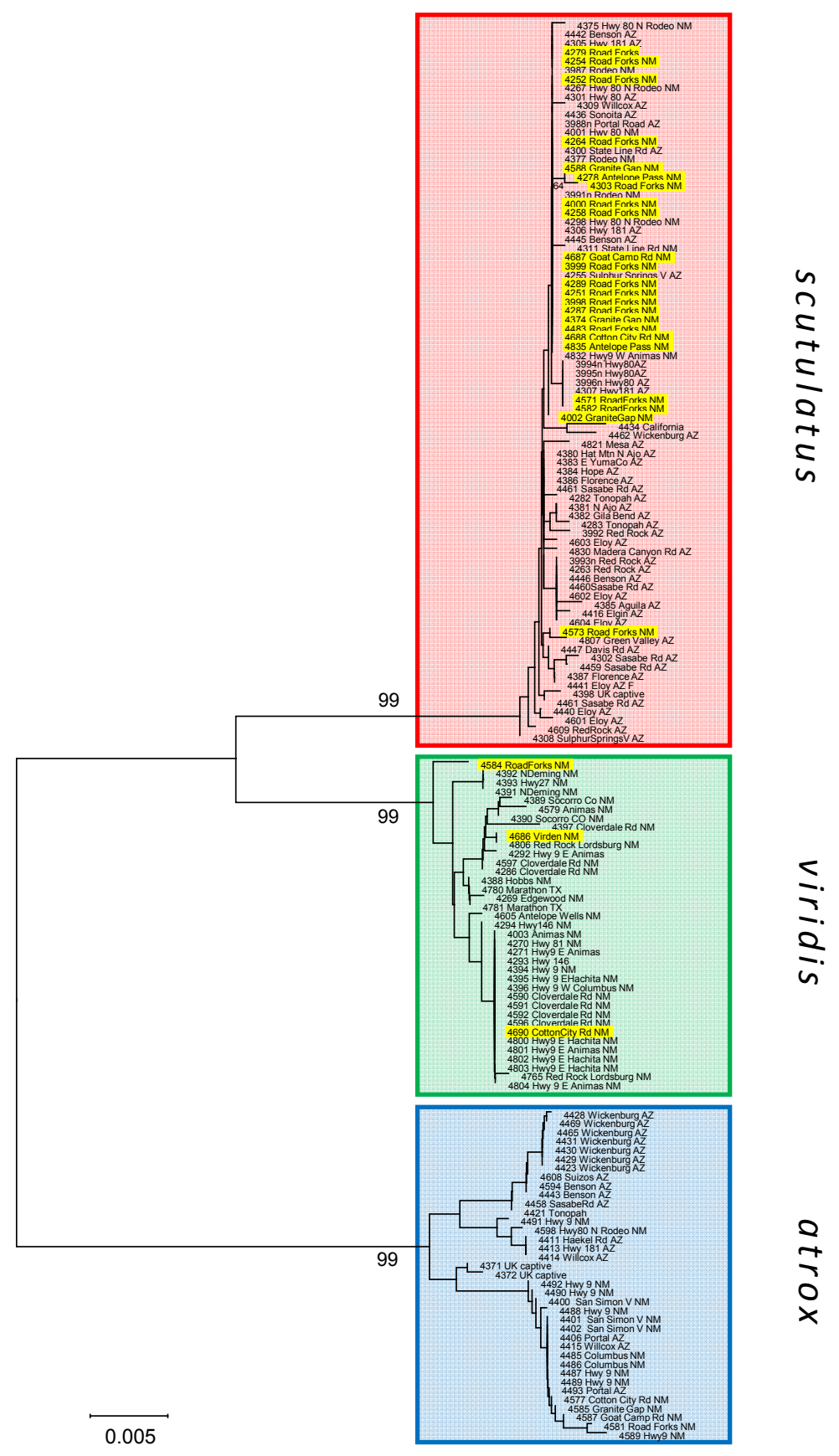

Figure 2. Neighbor-joining tree of individual ND4 sequences. Tip labels with yellow background indicate specimens from the putative hybrid zone in SW New Mexico. 
Bayesian clustering analysis of all three species using Structure 2.3.4 and $K=3$ showed extensive evidence of admixture between $C$. scutulatus and C. viridis, but virtually no evidence of hybridization between C. atrox and C. scutulatus or C. viridis (Figure 3A). Only one predominantly C. viridis specimen from the hybrid zone showed some evidence of admixture from both C. atrox and C. scutulatus. Specimens morphologically intermediate between C. scutulatus and C. atrox were identified genetically as being $C$. scutulatus $\times$ viridis or pure $C$. viridis, but in any case without admixture from $C$. atrox (Figure 3A).

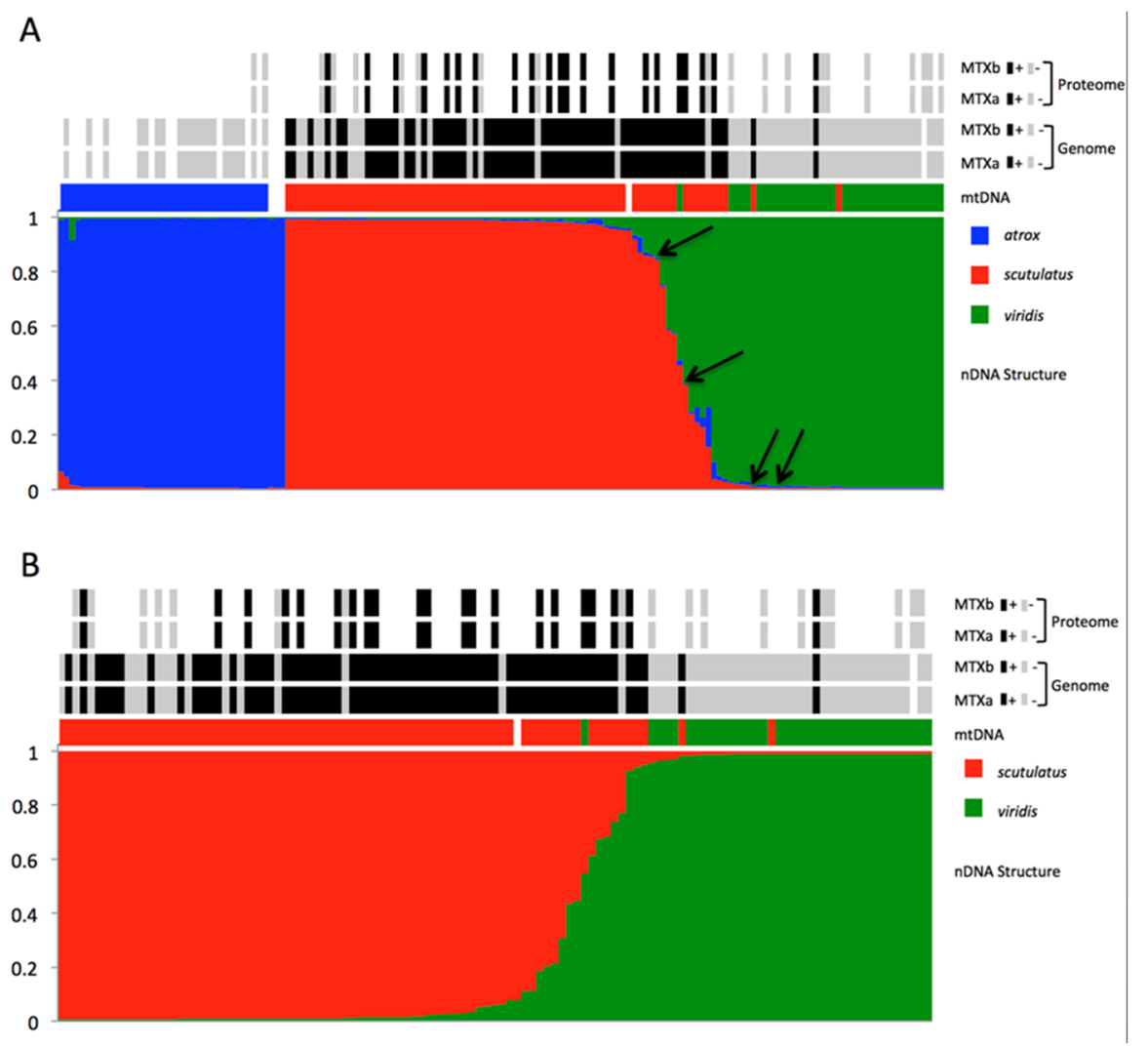

Figure 3. (A) Bayesian population clustering of individuals of C. atrox, C. scutulatus, C. viridis and putative hybrids based on allele frequencies of four single copy nuclear genes. Above the Structure clustering, rows of boxes indicate mtDNA haplotype affinities (same colors as nuclear structuring), and the presence (black) or absence (grey) of the genes coding for the basic and acidic subunits of Mojave toxin (MTX), and above the confirmed presence or absence of the corresponding proteins in the venom. White spaces indicate absence of data. Black arrows indicate specimens morphologically intermediate between C. scutulatus and C. atrox. (B) Equivalent analysis excluding C. atrox to emphasize hybrid zone between $C$. scutulatus and $C$. viridis.

Structure analysis of $C$. scutulatus and $C$. viridis individuals only, and $K=2$, showed a continuum of levels of admixture (Figure 3B). Virtually all specimens from outside the immediate vicinity of the hybrid zone showed less than $5 \%$ admixture from the other species, although the demarcation was sharper in C. viridis than C. scutulatus. Among admixed specimens, 14 displayed species membership (Qi) values between 0.7 and 0.95 , and seven Qi values between 0.5 and 0.7 , indicating the presence of backcrosses as well as F1 hybrids. Most of the admixed individuals had C. scutulatus mtDNA haplotypes, as did two specimens of $C$. viridis without evidence of admixture from near the main hybrid zone.

In all Structure analyses, independent and correlated frequency models generated functionally identical results. Only the former are presented here. 


\subsection{Detection of Mojave Toxin}

Newly designed primers for the acidic and basic subunits of MTX (MTXa and MTXb, respectively) produced fragments of 1246 b.p. of MTXa and 1266 b.p. of MTXb, including exon 3 and introns 2 and 3, as well as small stretches of exons 2 and 4 . The two MTX subunits were strictly linked: all specimens provided evidence of the genes for either both or neither of the subunits. We did not find any individuals with only one subunit. All partial sequences of the acidic and basic subunits were identical to or differed by no more than three (MTXa) and seven (MTXb) base pairs from the published sequence [53] (GenBank accession numbers U01026-7). Individuals of C. scutulatus lacking the MTX subunit genes were all from the documented zone of type I venom snakes in Central Arizona [21,54] (Figure 4). Within the hybrid zone, all MTX-positive individuals were either genetically pure C. scutulatus or showed evidence of admixture, either through their scnDNA profiles or possession of C. scutulatus mitochondrial haplotypes (Figure 3). The sole exception was an MTX-positive specimen of $C$. viridis without evidence of admixture from approximately $5 \mathrm{~km}$ east of a large number of MTX-positive admixed specimens. We did not find any MTX-positive $C$. viridis from locations more distant from the contact zone (Figure 4). None of the included C. atrox tested positive for either MTX subunit.

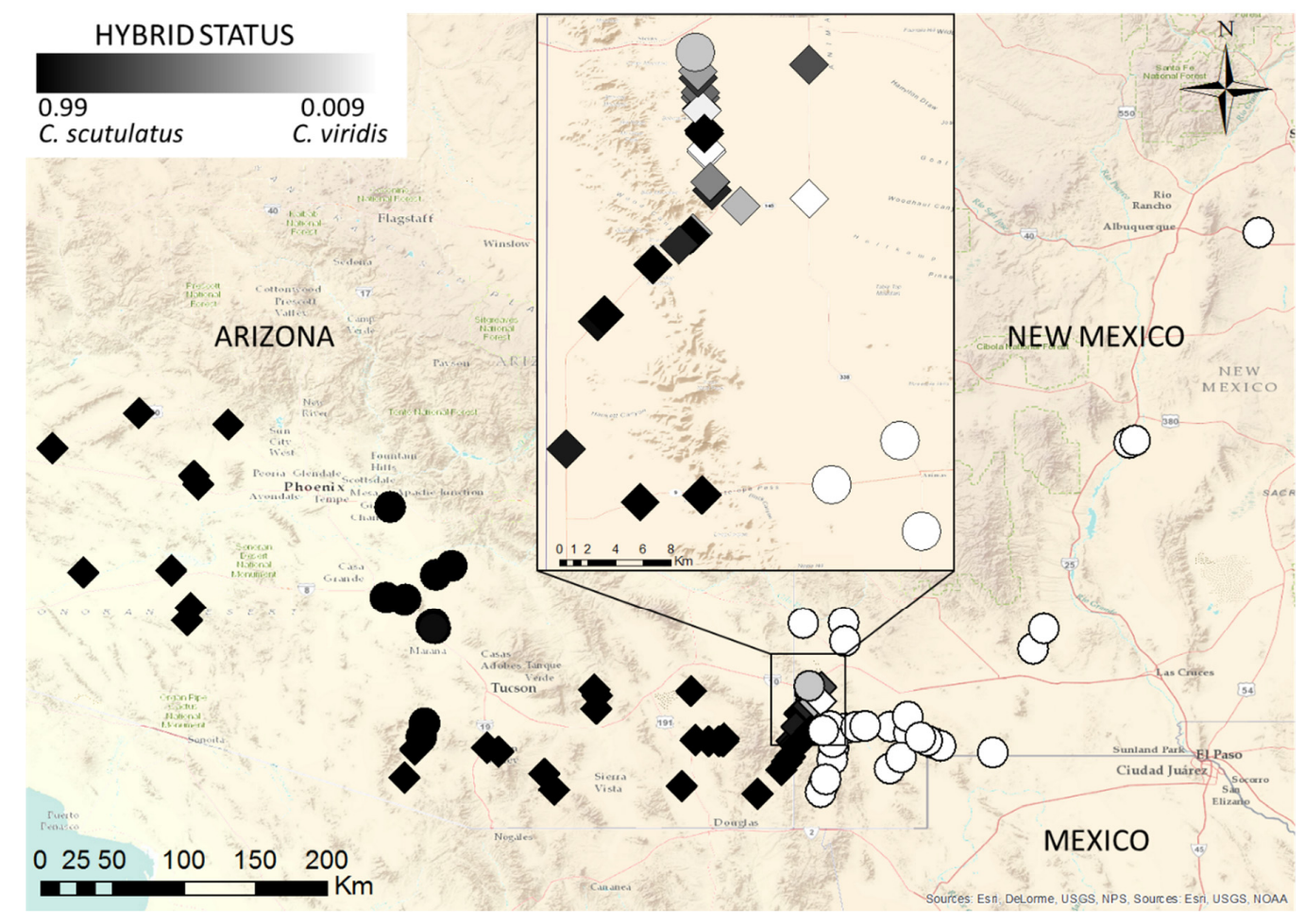

Figure 4. Sampling localities, hybrid status and MTX status of individuals of C. scutulatus, C. viridis and their hybrids. Diamonds indicate MTX+ve, circles MTX-ve individuals, the degree of shading of the symbols indicates the proportion of the genome attributed to C. scutulatus in the Structure analysis.

We obtained RP-HPLC profiles of the venoms of 41 snakes (two C. atrox, 20 C. scutulatus, 11 C. viridis, and eight putative hybrids). The characteristic peaks of the two MTX subunits [5] were unequivocally recognizable (Figure 5). Consistent with the genomic data, all examined venoms contained either both MTX subunits or neither. No venom showed evidence of only a single peak. Combining proteomic and genomic results revealed a strict linkage between genotype and phenotype: all available venoms from snakes with the MTX subunit genes displayed the two characteristic peaks corresponding to the basic and acidic subunits of MTX, whereas no individual lacking the genes produced them in the venom (Figure 3). 

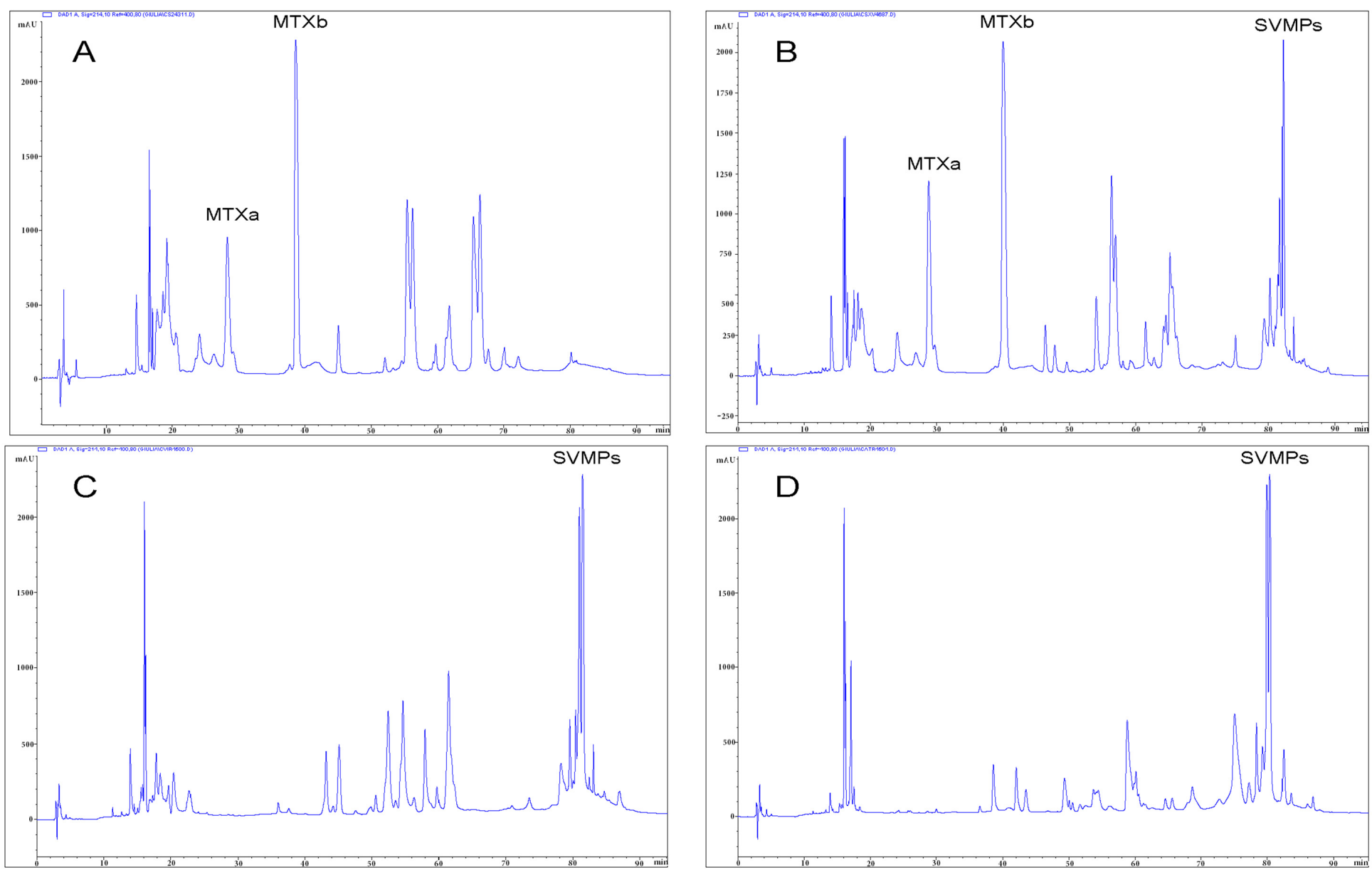

Figure 5. Examples of reverse-phase high performance liquid chromatography (RP-HPLC) chromatograms from different venoms included in the study. A. Crotalus scutulatus type II venom with MTX but lacking snake venom metalloproteinases (SVMPs); sample 4311, nr. Rodeo, Hidalgo Co., NM. B. Crotalus scutulatus $\times$ viridis, hybrid containing MTX and SVMPs; sample 4687, nr. Cotton City, Hidalgo Co., NM. C. Crotalus viridis, typical venom lacking MTX but containing SVMPs; sample 4590, nr. Animas, Hidalgo Co., NM. D. Crotalus atrox, typical venom lacking MTX but containing SVMPs; sample 4594, nr. Benson, Cochise Co., AZ. 


\section{Discussion}

In this study, we set out to test the hypothesis that interspecific hybridization would facilitate introgression by highly lethal presynaptic neurotoxin genes such as Mojave toxin, and thus lead to evolutionary changes in the venom composition of the receiving species. Our results do not support this hypothesis in this instance.

Our genetic analyses unequivocally demonstrate the existence of a narrow hybrid zone between Crotalus scutulatus and C. viridis along the eastern slope of the Peloncillo Mountains in Hidalgo County, southwestern New Mexico. Many, but not all, the specimens in the main hybrid area (Highway 80, within $18 \mathrm{~km}$ South of Road Forks, Hidalgo Co.) are recovered as genetically admixed in Structure analyses. Equally, many are morphologically intermediate between $C$. scutulatus and C. viridis. Our single copy nuclear gene data show a continuum of levels of admixture between C. scutulatus and C. viridis, indicating that many of the specimens are the result of backcrosses with either parental species. F1 hybrids between the two species are thus fertile and able to breed with either parent stock. Despite some morphological indications to the contrary, we found little genetic evidence of hybridization between $C$. atrox and either $C$. scutulatus or $C$. viridis. Individual specimens that were morphologically intermediate between $C$. scutulatus and C. atrox showed no genetic evidence of admixture from C. atrox, but appear to be C. scutulatus $\times$ viridis hybrids or backcrosses. Their phenetic resemblance to $C$. atrox is due to a tail pattern involving bands of greater width than found in $C$. viridis and equal width of dark and light bands, as found in C. atrox. So far, this is only the second genetically characterized hybrid zone between two venomous snake species (after the Vipera aspis $\times$ latastei hybrid zone in northern Spain, [55]).

Our results shed new light on the genetics of the MTX subunits. Contrary to Wooldridge et al. [28], we invariably found the genes encoding the basic and acidic subunits of MTX to be either both detectable or both absent in all specimens. Wooldridge et al. [28] reported that type I venom snakes lack only the gene encoding the acidic subunit, but retain the gene for the basic subunit. We were unable to replicate that result in our much larger sample. We suspect that their detection of the basic subunit gene in type I venom specimens may have been due to non-specific cross-amplification of other PLA 2 toxins by their primer set: we obtained sequences of PLA $_{2}$-like genes differing from the MTX basic subunit when using Wooldridge et al.'s basic subunit primers in specimens from the type I venom zone. Our redesigned primers (see methods) did not incur this problem, and all sequence-confirmed positive PCRs were identical to within a few base pairs with the published MTX sequences [53]. These data suggest that the two subunits are tightly linked in the genome of $C$. scutulatus, presumably due to close proximity on the same chromosome.

Furthermore, our results demonstrate an absolute genotype-phenotype link for the two MTX subunit genes: every single tested specimen with positive PCR results for the MTX subunits yielded HPLC profiles with the two characteristic peaks corresponding to the MTX subunits [5], whereas no specimen without the genes yielded those peaks. This applied independently of genetic profile or hybrid status, and demonstrates that genotypic differences are reflected in the phenotype, and thus provide potential targets for natural selection. This situation contrasts with that found in other viperids, e.g., Echis, in which selective transcription and translation as well as post-translational modifications play a prominent part in shaping venom composition [56].

Both subunits of MTX were present in most $C$. scutulatus (except from the previously documented area of type I venom snakes in central Arizona, [21]), but absent from most $C$. viridis. In southwestern New Mexico, only genetically "pure" C. scutulatus or individuals with clearly admixed genotypes were positive for both MTX subunits, with the exception of three specimens identified as genetically pure $C$. viridis based on scnDNA markers that were positive for the MTX subunits. Two showed evidence of admixture in the shape of $C$. scutulatus ND4 haplotypes, and all three were from the immediate vicinity of the hybrid zone and surrounded by other admixed specimens. Overall, there is no evidence of introgression of MTX genes into the genome of $C$. viridis beyond the hybrid zone and its immediate vicinity. We suspect that the snakes identified as Mojave toxin-bearing C. viridis by 
Glenn and Straight [37] were in reality hybrids from the zone documented here, although this cannot be verified in the absence of precise locality information in that paper.

The absence of either subunit of MTX in any of our C. atrox is consistent with the lack of admixture between this species and the others, as well as most of the literature on the species, although Minton and Weinstein [57] did report low concentrations of MTX from a few specimens of $C$. atrox. The lack of admixture between $C$. atrox and C. scutulatus in our data also argues against a role for hybridization between these two species in generating the type I venom population of C. scutulatus in Central Arizona, as hypothesized by Aird et al. [38]. None of our MTX-negative C. scutulatus showed evidence of admixture from C. atrox, and neither did any other $C$. scutulatus in our sample, a result consistent with previous analyses [51].

The failure of the MTX genes to spread into the range of $C$. viridis argues against the hypothesis that highly lethal neurotoxins necessarily represent a strong adaptive advantage for rattlesnakes. The parapatry between these two closely related species of rattlesnakes represents a best-case scenario for adaptive introgression of toxin-encoding genes: other things being equal, closely related species are more likely to be reproductively compatible than distantly related species, hybrids are likely to incur a lower loss of fitness than hybrids between more distantly related species, and it is less likely that linked, selectively disadvantageous loci will slow the spread of advantageous toxin genes [34,35]. The imperviousness of the gene pool of $C$. viridis to penetration by the MTX genes thus suggests that possession of these highly lethal neurotoxins is not necessarily a strong selective advantage. Clearly, we cannot exclude the possibility of a different outcome under other circumstances, such as different selective regimes or different constellations of linked genes. Moreover, since we do not know the age of this contact zone, we cannot reject the possibility that, given sufficient time, a degree of introgression of MTX genes may occur. However, given the results presented here, we conclude that the C. scutulatus $\times$ viridis hybrid zone does not provide evidence favoring the hypothesis that limited hybridization may be enough to facilitate the wider and relatively rapid spread of toxin genes in a species in which they were previously missing.

Hybridization has been invoked as a cause of venom variation in multiple groups of snakes $[30,38,39]$, but with little evidence beyond incongruence between phylogeny and venom composition. The rigorous genetic identification of additional hybrid zones between venomous snake species could make a significant contribution to our understanding of venom evolution and the role of adaptive hybridization therein. Until then, based on the results presented herein, we suggest that hybridization should not be invoked as an explanation for unexpected patterns of inter- and intraspecific variation in snake venom composition or for unusual cases of clinical snakebite envenoming without compelling evidence.

\section{Materials and Methods}

\subsection{Morphological Methods}

From digital photos of 245 field-captured specimens, we recorded nine characters of head scalation and tail pattern (Table 2). We used the software MVSP 3.2 (Kovach Computing Services, Pentraeth, UK, 2007) to perform a Principal Components Analysis after data standardization to zero mean and unit standard deviation. 
Table 2. Morphological characters used for assessment of hybridization. Terminology for head scales follows [45].

\begin{tabular}{l}
\hline 1. Number of internasals contacting rostral scale \\
\hline 2. Minimum number of scales separating posteriormost canthals \\
\hline 3. Minimum number of scales separating supraoculars \\
\hline 4. Number of scales contacting the inner edge of the supraoculars \\
\hline 5. Number of dark (defined as noticeably darker than body markings) bands on tail \\
\hline 6. Number of light (defined as noticeably lighter than body ground colour) bands on tail \\
\hline 7. Maximum width in dorsal scale lengths along a single scale row (excluding the vertebral row) of the \\
posteriormost black band not contacting the rattle fringe. \\
\hline 8. Maximum width in dorsal scale lengths along a single scale row (excluding the vertebral row) of the light \\
band anterior to 7.
\end{tabular}

\subsection{Molecular Analysis of Hybridization}

We obtained tissue samples (ventral scale clippings or shed skin) from 156 rattlesnakes, including field-caught specimens of C. scutulatus, C. viridis and C. atrox from throughout southern Arizona and New Mexico, and additional samples from colleagues and collaborators in the institutional and private sector. All field-collected specimens were released unharmed at the precise locality of capture within $72 \mathrm{~h}$. Total genomic DNA was extracted using the DNeasy Blood and Tissue kit (Qiagen, Düsseldorf, Germany) following the manufacturer's instructions.

For the assessment of hybridization, we PCR-amplified one mitochondrial gene fragment (NADH dehydrogenase subunit 4-hereafter ND4), and four single-copy nuclear loci: neurotrophin 3 (NT3, S. Cremer, unpublished), R35 [58], ETS oncogene [59], and SELT [60]. PCR was carried out in final volumes of $15 \mu \mathrm{L}$ containing $1 \times$ ReddyMix PCR Master Mix (Thermo Scientific, Waltham, MA USA), $0.3 \mu \mathrm{M}$ forward and reverse primers, and $1 \mu \mathrm{L}$ of genomic DNA (approximate concentration $20 \mathrm{ng} / \mu \mathrm{L}$ ). Primers and cycling conditions are given in Appendix A. Sanger chain termination direct sequencing was carried out at Macrogen, Seoul, South Korea. Nuclear loci were sequenced using both sense and antisense primers.

Sequence traces were checked for quality and aligned in CodonCode Aligner version 3.7.1 (CodonCode Corporation, Centerville, MA, USA). All coding sequences were translated to check that no frameshift mutations or unexpected stop codons were present. Heterozygous positions in nuclear sequences were identified by a combination of visual inspection for double peaks and typically low quality Phred scores [61] for the bases surrounding a heterozygous position. The individual alleles of length heterozygotes (in SELT only) were reconstructed using the online utility Indelligent v. 1.2 [62]. Individual allele sequences (haplotypes) were estimated from diploid nuclear loci using the software PHASE v. 2.1.1 [63,64] over 10,000 iterations with a burn-in of 5000 and a thinning interval of 100 for ETS, R35 and SELT, and 30,000, 15,000 and 300, respectively, for NT3, after preparation of the sequence data using SEQPHASE [65]. PHASE was run three times to confirm burn-in and convergence across multiple runs, and the highest probability haplotype pair for each specimen was retained for further analysis.

We determined the matrilineal line of descent of each specimen through a neighbor-joining tree of mitochondrial ND4 sequences. The analysis was run in MEGA 6.0.6 [66], using the maximum composite likelihood distance model, pairwise deletion of sites with missing base pairs, and 1000 bootstrap replicates. To visualize patterns of hybridization between species, we analyzed the nuclear genes with the Bayesian clustering method implemented in the software Structure 2.3.4 [67,68]. The analysis was run using an admixture model and both independent and correlated allele frequency models [69]. In the initial analyses run under inclusion of $C$. atrox, $\mathrm{K}$ was set to 3, reflecting the presence 
of three species in the dataset. After exclusion of C. atrox, the analysis was rerun solely on samples of C. scutulatus and $C$. viridis and likely hybrids between them, with $\mathrm{K}$ set to 2 . All analyses were run over 100,000 iterations after a burn-in of 100,000 iterations, and in triplicate to check the consistency of results.

\subsection{Determination of Mojave Toxin Presence}

We used PCR amplification to test for the presence of the genes encoding the basic and acidic subunits of Mojave toxin in all specimens. Since the basic subunit primers from Wooldridge et al. [28] resulted in the amplification of $\mathrm{PLA}_{2} \mathrm{~S}$ other than Mojave toxin in some MTX-negative individuals, we designed novel primers extending from exon 2 to exon 4 of the published MTX sequences of John et al. [53] (Genbank-acidic: U01026; basic: U01027). We verified the identity of all positive PCR products by Sanger sequencing (Macrogen, Seoul, South Korea). Primers and PCR conditions are given in Appendix A. Verification and alignment of the sequences against the published MTX sequences followed the procedures outlined for single copy nuclear genes above. Since even minimal contamination across samples can lead to false positive PCR results, anomalous or inconsistent results were checked by PCR amplification from fresh DNA extracts.

\subsection{Determination of Mojave Toxin in the Venom}

Approximately $0.7 \mathrm{mg}$ of crude venoms from 41 specimens were separated by reverse-phase HPLC using a Teknokroma Europa 300 C18 column $(250 \times 4$ mm, $5 \mu \mathrm{m}$ particle size, Teknokroma, Barcelona, Spain) eluting at $1 \mathrm{~mL} / \mathrm{min}$ with a linear gradient of $0.1 \%$ TFA in water and acetonitrile. Presence of the two MTX subunits was determined by comparing our chromatograms to those published in Massey et al. [5].

Acknowledgments: We thank our numerous friends and collaborators in Arizona and New Mexico and elsewhere who assisted with our sampling and field work: David and Peggy Alvarado, Bob and Sheri Ashley, Chip Blackburn, Chip Cochran, David Deem, Sean Graham, Ronald Govreau, Kris Haas, Catriona Hendry, Hans-Werner Herrmann, James Hicks, Jason Houck, Bryan Hughes, Terry A. Johnson, Dominic Lannutti, Richard Legere, Peter Lindsey, Simon Maddock, José Maldonado, David and Ronda Mills, Mrinalini, Ed Myers, David Nixon, Diego Ortiz, Adrian Quijada-Mascareñas, Jill Rials, David Richards, Ryan Sawby, Gordon Schuett, Bryan Starrett, Sky Stevens, Jason Strickland, Taylor Tevis, Barney Tomberlin, Curt Vratil, David Weber. For laboratory advice and assistance, we gratefully acknowledge Julianne Goldenberg, Wendy Grail and Katie Coburn. Robert Aldridge, Chloe McLaughlin, Victoria Payne, Kristian Settle-Whittaker and Dean Williams generated some of the MTX gene sequences. The Arizona Game and Fish Department and the New Mexico Department of Game and Fish courteously and efficiently issued collecting permits and assisted with queries.

Funded by Leverhulme Trust grant RPG-2013-315 to Wolfgang Wüster and Grant BFU2013-42833-P from the Ministerio de Economía y Competitividad, Madrid (Spain) to Juan J. Calvete.

Author Contributions: Wolfgang Wüster, Axel Barlow and Giulia Zancolli conceived and designed the experiments; Giulia Zancolli, Axel Barlow, Catharine E. Wüster and Wolfgang Wüster carried out field work and sampling; Giulia Zancolli, Timothy G. Baker, Rebecca K. Bradley, Juan J. Calvete, Kimberley C. Carter, Kaylah de Jager, John Benjamin Owens, Jenny Forrester Price, Libia Sanz, Amy Scholes-Higham, Liam Shier and Liam Wood performed the experiments; Giulia Zancolli and Wolfgang Wüster analyzed the data; Juan J. Calvete and Libia Sanz contributed reagents, materials and analysis tools; Wolfgang Wüster wrote the paper.

Conflicts of Interest: The authors declare no conflict of interest.

\section{Abbreviations}

The following abbreviations are used in this manuscript:

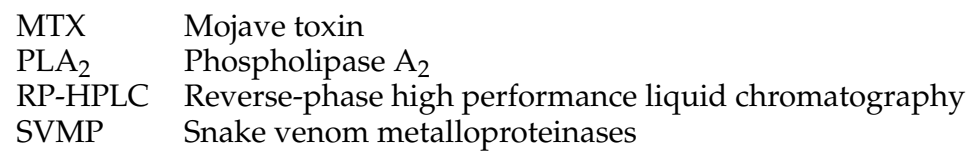

\section{Appendix A}

Primer sequences (Table A1, references in main text) and PCR conditions (Table A2). 
Table A1. Primer names and sequences for each locus.

\begin{tabular}{lll}
\hline Locus & Forward & Reverse \\
\hline ND4 & ND4: & Leu:CATTACTTTTACTTGGATTTGCACCA \\
NT3 & NTF3_SC_F: CGACGGTTTTGCACTGGGAAT & H12763V: TTCTATCACTTGGATTGCACCA \\
R35 & R35_F: GACTGTGGAYGAYCTGATCAGTGTGGTGCC & R35_R: GCCAAAATTGCAGGGGGGGATCCA \\
SELT & SELT_F: GTTATYAGCCAGCGGTACCCAGACATCCG & SELT_R: GCCTATTAAYACTAGTTTGAAGAGACTGAGC \\
ETS & ETS_F: CCATCAACAGACACACAGG & ETS_R: GTCTGCTTTTTACTTTGCG \\
MTXa & MTXa2_F: TGCGGGGAGAAGTGGTATTT & MTXa4_R: GCAATTTTCGGGCGAGAACC \\
MTXb & MTXb2_F: ACCTGCTGCAATTCAACAAGA & MTXb4_R: CGAGAGTCCGGGTAAAACAT \\
\hline
\end{tabular}

Table A2. PCR conditions for each locus.

\begin{tabular}{ccccc}
\hline PCR Parameter & ND4 & NT3/R35 & SELT/ETS & MTXa/MTXb \\
\hline 1. Initial denaturation & $94^{\circ}-2 \mathrm{~m}$ & $94^{\circ}-2 \mathrm{~m}$ & $94^{\circ}-2 \mathrm{~m}$ & $94^{\circ}-2 \mathrm{~m}$ \\
2. Denaturation & $94^{\circ}-30 \mathrm{~s}$ & $94^{\circ}-30 \mathrm{~s}$ & $94^{\circ}-30 \mathrm{~s}$ & $94^{\circ}-30 \mathrm{~s}$ \\
3. Annealing & $57^{\circ}-30 \mathrm{~s}$ & $55^{\circ}-1 \mathrm{~m}$ & $47^{\circ}-1 \mathrm{~m}$ & $59^{\circ}-30 \mathrm{~s}$ \\
4. Extension & $72^{\circ}-1 \mathrm{~m}$ & $72^{\circ}-1 \mathrm{~m}$ & $72^{\circ}-1 \mathrm{~m}$ & $72^{\circ}-1.5 \mathrm{~m}$ \\
5. No. Cycles (2-4) & 40 & 35 & 35 & 35 \\
6. Final extension & $72^{\circ}-5 \mathrm{~m}$ & $72^{\circ}-5 \mathrm{~m}$ & $72^{\circ}-5 \mathrm{~m}$ & $72^{\circ}-5 \mathrm{~m}$ \\
\hline
\end{tabular}

\section{References}

1. Chippaux, J.P.; Williams, V.; White, J. Snake Venom Variability: Methods of study, results and interpretation. Toxicon: Off. J. Int. Soc. Toxinol. 1991, 29, 1279-1303. [CrossRef]

2. Casewell, N.R.; Wüster, W.; Vonk, F.J.; Harrison, R.A.; Fry, B.G. Complex cocktails: The evolutionary novelty of venoms. Trends Ecol. Evol. 2013, 28, 219-229. [CrossRef] [PubMed]

3. Warrell, D.A. Snake venoms in science and clinical medicine. 1. Russell's viper: Biology, venom and treatment of bites. Trans. R. Soc. Trop. Med. Hyg. 1989, 83, 732-740. [CrossRef]

4. Warrell, D.A. Geographical and intraspecies variation in the clinical manifestations of envenoming by snakes. Symp. Zool. Soc. Lond. 1997, 70, 189-203.

5. Massey, D.J.; Calvete, J.J.; Sánchez, E.E.; Sanz, L.; Richards, K.; Curtis, R.; Boesen, K. Venom variability and envenoming severity outcomes of the Crotalus. scutulatus scutulatus (Mojave rattlesnake) from Southern Arizona. J. Proteom. 2012, 75, 2576-2587. [CrossRef] [PubMed]

6. Ogawa, T.; Nakashima, K.; Nobuhisa, I.; Deshimaru, M.; Shimohigashi, Y.; Fukumaki, Y.; Sakaki, Y.; Hattori, S.; Ohno, M. Accelerated evolution of snake venom phospholipase A2 isozymes for acquisition of diverse physiological functions. Toxicon: Off. J. Int. Soc. Toxinol. 1996, 34, 1229-1236. [CrossRef]

7. Lynch, V.J. Inventing an arsenal: Adaptive evolution and neofunctionalization of snake venom phospholipase A(2) genes. BMC Evol. Biol. 2007, 7, 2. [CrossRef] [PubMed]

8. Gibbs, H.L.; Rossiter, W. Rapid evolution by positive selection and gene gain and loss: PLA 2 venom genes in closely related Sistrurus. rattlesnakes with divergent diets. J. Mol. Evol. 2008, 66, 151-166. [CrossRef] [PubMed]

9. Daltry, J.C.; Wüster, W.; Thorpe, R.S. Diet and snake venom evolution. Nature 1996, 379, 537-540. [CrossRef] [PubMed]

10. Thorpe, R.S.; Pook, C.E.; Malhotra, A. Phylogeography of the Russell's viper (Daboia. russelii) complex in relation to variation in the colour pattern and symptoms of envenoming. Herpetol. J. 2007, 17, 209-218.

11. Jorge da Silva, N.; Aird, S.D. Prey specificity, comparative lethality and compositional differences of coral snake venoms. Comp. Biochem. Physiol. C 2001, 128, 425-456. [CrossRef]

12. Barlow, A.; Pook, C.E.; Harrison, R.A.; Wüster, W. Co-evolution of diet and prey-specific venom activity supports the role of selection in snake venom evolution. Proc. R. Soc. B 2009, 276, 2443-2449. [CrossRef] [PubMed]

13. Gibbs, H.L.; Mackessy, S.P. Functional basis of a molecular adaptation: Prey-specific toxic effects of venom from Sistrurus rattlesnakes. Toxicon: Off. J. Int. Soc. Toxinol. 2009, 53, 672-679. [CrossRef] [PubMed] 
14. Glenn, J.L.; Straight, R.C. Mojave rattlesnake Crotalus. scutulatus scutulatus venom: Variation in toxicity with geographical origin. Toxicon: Off. J. Int. Soc. Toxinol. 1978, 16, 81-84. [CrossRef]

15. McCue, M.D. Enzyme activities and biological functions of snake venoms. Appl. Herpetol. 2005, 2, 109-123. [CrossRef]

16. Mackessy, S.P. Venom composition in rattlesnakes: Trends and biological significance. In The Biology of the Rattlesnakes; Hayes, W.K., Beaman, K.R., Cardwell, M.D., Bush, S.P., Eds.; Loma Linda University Press: Loma Linda, CA, USA, 2008; pp. 495-510.

17. Mackessy, S.P.; Williams, K.; Ashton, K.G. Ontogenetic variation in venom composition and diet of Crotalus oreganus concolor: A case of venom paedomorphosis? Copeia 2003, 2003, 769-782. [CrossRef]

18. Mackessy, S.P. Evolutionary trends in venom composition in the Western Rattlesnakes (Crotalus viridis sensu lato): Toxicity vs. tenderizers. Toxicon: Off. J. Int. Soc. Toxinol. 2010, 55, 1463-1474. [CrossRef] [PubMed]

19. Glenn, J.L.; Straight, R.C. Distribution of proteins immunologically similar to Mojave toxin among species of Crotalus and Sistrurus. Toxicon: Off. J. Int. Soc. Toxinol. 1985, 23, 28.

20. Glenn, J.L.; Straight, R.C. Intergradation of two different venom populations of the Mojave rattlesnake (Crotalus scutulatus scutulatus) in Arizona. Toxicon: Off. J. Int. Soc. Toxinol. 1989, 27, 411-418. [CrossRef]

21. Glenn, J.L.; Straight, R.C.; Wolfe, M.C.; Hardy, D.L. Geographical variation in Crotalus scutulatus scutulatus (Mojave rattlesnake) venom properties. Toxicon: Off. J. Int. Soc. Toxinol. 1983, 21, 119-130. [CrossRef]

22. Powell, R.L.; Lieb, C.S.; Rael, E.D. Geographic distribution of Mojave toxin and Mojave toxin subunits among selected Crotalus species. Venom composition in rattlesnakes: Trends and biological significance. In The Biology of the Rattlesnakes; Hayes, W.K., Beaman, K.R., Cardwell, M.D., Bush, S.P., Eds.; Loma Linda University Press: Loma Linda, CA, USA, 2008; pp. 537-550.

23. Durban, J.; Pérez, A.; Sanz, L.; Gómez, A.; Bonilla, F.; Rodríguez, S.; Chacón, D.; Sasa, M.; Angulo, Y.; Gutiérrez, J.M.; et al. Integrated "omics" profiling indicates that miRNAs are modulators of the ontogenetic venom composition shift in the Central American rattlesnake Crotalus simus simus. BMC Genom. 2013, 14, 234. [CrossRef] [PubMed]

24. Sunagar, K.; Undheim, E.A.B.; Scheib, H.; Gren, E.C.K.; Cochran, C.; Person, C.E.; Koludarov, I.; Kelln, W.; Hayes, W.K.; King, G.F.; et al. Intraspecific venom variation in the medically significant Southern Pacific Rattlesnake (Crotalus oreganus helleri): Biodiscovery, clinical and evolutionary implications. J. Proteom. 2014, 99, 68-83. [CrossRef] [PubMed]

25. Saravia, P.; Rojas, E.; Arce, V.; Guevara, C.; López, J.C.; Chaves, E.; Velásquez, R.; Rojas, G.; Gutiérrez, J.M. Geographic and ontogenic variability in the venom of the neotropical rattlesnake Crotalus durissus: pathophysiological and therapeutic implications. Rev. Biol. Trop. 2002, 50, 337-346. [PubMed]

26. Calvete, J.J.; Sanz, L.; Cid, P.; de la Torre, P.; Flores-Díaz, M.; dos Santos, M.C.; Borges, A.; Bremo, A.; Angulo, Y.; Lomonte, B.; Alape-Girón, A.; Gutiérrez, J.M. Snake venomics of the Central American Rattlesnake Crotalus simus and the South American Crotalus durissus complex points to neurotoxicity as an adaptive paedomorphic trend along Crotalus dispersal in South America. J. Proteome Res. 2010, 9, 528-544. [CrossRef] [PubMed]

27. Glenn, J.L.; Straight, R.C.; Wolt, T.B. Regional variation in the presence of canebrake toxin in Crotalus horridus venom. Comp. Biochem. Physiol. C 1994, 107, 337-346. [CrossRef]

28. Wooldridge, B.J.; Pineda, G.; Banuelas-Ornelas, J.J.; Dagda, R.K.; Gasanov, S.E.; Rael, E.D.; Lieb, C.S. Mojave rattlesnakes (Crotalus scutulatus scutulatus) lacking the acidic subunit DNA sequence lack Mojave toxin in their venom. Comp. Biochem. Physiol. B 2001, 130, 169-179. [CrossRef]

29. Sánchez, E.E.; Galán, J.A.; Powell, R.L.; Reyes, S.R.; Soto, J.G.; Russell, W.K.; Russell, D.H.; Pérez, J.C. Disintegrin, hemorrhagic, and proteolytic activities of Mohave rattlesnake, Crotalus scutulatus scutulatus venoms lacking Mojave toxin. Comp. Biochem. Physiol. C 2005, 141, 124-132. [CrossRef] [PubMed]

30. Rokyta, D.R.; Wray, K.P.; McGivern, J.J.; Margres, M.J. The transcriptomic and proteomic basis for the evolution of a novel venom phenotype within the Timber Rattlesnake (Crotalus horridus). Toxicon: Off. J. Int. Soc. Toxinol. 2015, 98, 34-48. [CrossRef] [PubMed]

31. Lewontin, R.C.; Birch, L.C. Hybridization as a source of variation for adaptation to new environments. Evolution 1966, 20, 315-336. [CrossRef]

32. Hedrick, P.W. Adaptive introgression in animals: Examples and comparison to new mutation and standing variation as sources of adaptive variation. Mol. Ecol. 2013, 22, 4606-4618. [CrossRef] [PubMed]

33. Barton, N.H. Gene flow past a cline. Heredity 1979, 43, 333-339. [CrossRef] 
34. Harrison, R.G.; Larson, E.L. Hybridisation, introgression, and the nature of species boundaries. J. Hered. 2014, 105, 795-809. [CrossRef] [PubMed]

35. Uecker, H.; Setter, D.; Hermisson, J. Adaptive gene introgression after secondary contact. J. Math. Biol. 2015, 70, 1523-1580. [CrossRef] [PubMed]

36. Barton, N.H.; Hewitt, G.M. Analysis of hybrid zones. Ann. Rev. Ecol. Syst. 1985, 16, 113-148. [CrossRef]

37. Glenn, J.L.; Straight, R.C. Venom characteristics as an indicator of hybridisation between Crotalus viridis viridis and Crotalus scutulatus scutulatus in New Mexico. Toxicon: Off. J. Int. Soc. Toxinol. 1990, 28, 857-862. [CrossRef]

38. Aird, S.D.; Thirkhill, L.J.; Seebart, C.S.; Kaiser, I.I. Venoms and Morphology of Western Diamondback/Mojave Rattlesnake Hybrids. J. Herpetol. 1989, 23, 131-141. [CrossRef]

39. Wang, Y.-M.; Parmelee, J.; Guo, Y.-W.; Tsai, I.-H. Absence of phospholipase A2 in most Crotalus horridus venom due to translation blockage: Comparison with Crotalus horridus atricaudatus venom. Toxicon: Off. J. Int. Soc. Toxinol. 2010, 56, 93-100. [CrossRef] [PubMed]

40. Guillemin, I.; Bouchier, C.; Garrigues, T.; Wisner, A.; Choumet, V. Sequences and structural organization of phospholipase A2 genes from Vipera aspis aspis, V. aspis zinnikeri and Vipera berus berus venom. Identification of the origin of a new viper population based on ammodytin I1 heterogeneity. Eur. J. Biochem. 2003, 270, 2697-2706. [CrossRef] [PubMed]

41. Ferquel, E.; de Haro, L.; Jan, V.; Guillemin, I.; Jourdain, S.; Teynié, A.; d'Alayer, J.; Choumet, V. Reappraisal of Vipera aspis venom neurotoxicity. PLoS ONE 2007, 2. [CrossRef] [PubMed]

42. Grenard, S. Is rattlesnake venom evolving? Nat. Hist. Mag. 2000, 109, 44-46.

43. Hayes, W.K.; Mackessy, S.P. Sensationalistic journalism and tales of snakebite: Are rattlesnakes rapidly evolving more toxic venom? Wild. Environ. Med. 2010, 21, 35-45. [CrossRef] [PubMed]

44. Galán, J.A.; Sánchez, E.E.; Rodríguez-Acosta, A.; Pérez, J.C. Neutralization of venoms from two Southern Pacific Rattlesnakes (Crotalus helleri) with commercial antivenoms and endothermic animal sera. Toxicon: Off. J. Int. Soc. Toxinol. 2004, 43, 791-799. [CrossRef] [PubMed]

45. Klauber, L.M. Rattlesnakes: Their Habits, Life Histories, and Influence on Mankind, 2nd ed.; University of California Press: Berkeley, CA, USA, 1972.

46. Campbell, J.A.; Lamar, W.W. The Venomous Reptiles of Latin America; Comstock: Ithaca, NY, USA/London, UK, 1989.

47. Campbell, J.A.; Brodie, E.D.; Barker, D.G.; Price, A.H. An apparent natural hybrid rattlesnake and Crotalus willardi (Viperidae) from the Peloncillo Mountains of southwestern New Mexico. Herpetologica 1989, 45, 344-349.

48. Meik, J.M.; Fontenot, B.E.; Franklin, C.J.; King, C. Apparent natural hybridization between the rattlesnakes Crotalus atrox and C. horridus. Southwest. Nat. 2008, 53, 196-200. [CrossRef]

49. Montgomery, W.B.; Schuett, G.W.; Douglas, M.R.; Douglas, M.E. Crotalus atrox x Crotalus horridus (Western diamond-backed rattlesnake x timber rattlesnake). Natural Hybrid. Herpetol. Rev. 2013, 44, 689.

50. Murphy, R.W.; Crabtree, B.C. Genetic Identification of a Natural Hybrid Rattlesnake: Crotalus scutulatus scutulatus x C. viridis viridis. Herpetologica 1988, 44, 119-123.

51. Jacob, J.S. An evaluation of the possibility of hybridization between the rattlesnakes Crotalus atrox and C. scutulatus in the Southwestern United States. Southwest. Nat. 1977, 22, 469-485. [CrossRef]

52. Degenhardt, W.G.; Painter, C.W.; Price, A.H. Amphibians and Reptiles of New Mexico; University of New Mexico Press: Albuquerque, NM, USA, 2005.

53. John, T.R.; Smith, L.A.; Kaiser, I.I. Genomic sequences encoding the acidic and basic subunits of Mojave toxin: Unusually high sequence identity of non-coding regions. Gene 1994, 139, 229-234. [CrossRef]

54. Wilkinson, J.A.; Glenn, J.L.; Straight, R.C.; Sites, J.W. Distribution and genetic variation in venom A and B populations of the Mojave rattlesnake (Crotalus scutulatus scutulatus) in Arizona. Herpetologica 1991, 47, 54-68.

55. Tarroso, P.; Pereira, R.J.; Martínez-Freiría, F.; Godinho, R.; Brito, J.C. Hybridization at an ecotone: Ecological and genetic barriers between three Iberian vipers. Mol. Ecol. 2014, 23, 1108-1123. [CrossRef] [PubMed]

56. Casewell, N.R.; Wagstaff, S.C.; Wüster, W.; Cook, D.A.N.; Bolton, F.M.S.; King, S.I.; Pla, D.; Sanz, L.; Calvete, J.J.; Harrison, R.A. Medically important differences in snake venom composition are dictated by distinct postgenomic mechanisms. PNAS 2014, 111, 9205-9210. [CrossRef] [PubMed] 
57. Minton, S.A.; Weinstein, S.A. Geographic and ontogenetic variation in venom of the western diamondback rattlesnake (Crotalus atrox). Toxicon. 1986, 24, 71-80. [CrossRef]

58. Vidal, N.; Delmas, A.-S.; David, P.; Cruaud, C.; Couloux, A.; Hedges, S.B. The phylogeny and classification of caenophidian snakes inferred from seven nuclear protein-coding genes. C. R. Biol. 2007, 330, 182-187. [CrossRef] [PubMed]

59. Gibbs, H.L.; Diaz, J. Identification of single copy nuclear DNA markers for North American pit vipers. Mol. Ecol. Resour. 2010, 10, 177-180. [CrossRef] [PubMed]

60. Goldenberg, J.R. Multilocus species delimitation and species tree inference within the western rattlesnake (Crotalus viridis) species complex. Unpublished MS Thesis, San Diego State University, San Diego, CA, USA, May 2013.

61. Ewing, B.; Green, P. Base-calling of automated sequencer traces using Phred. II. Error probabilities. Genome Res. 1998, 8, 186-194.

62. Dmitriev, D.A.; Rakitov, R.A. Decoding of superimposed traces produced by direct sequencing of heterozygous indels. PLoS Comput. Biol. 2008, 4. [CrossRef] [PubMed]

63. Stephens, M.; Smith, N.; Donnelly, P. A new statistical method for haplotype reconstruction from population data. Am. J. Human Genet. 2001, 68, 978-989. [CrossRef] [PubMed]

64. Stephens, M.; Scheet, P. Accounting for Decay of Linkage Disequilibrium in Haplotype Inference and Missing-Data Imputation. Am. J. Human Genet. 2005, 76, 449-462. [CrossRef] [PubMed]

65. Flot, J.-F. SeqPHASE: A web tool for interconverting PHASE input/output files and FASTA sequence alignments. Mol. Ecol. Resour. 2010, 10, 162-166. [CrossRef] [PubMed]

66. Tamura, K.; Stecher, G.; Peterson, D.; Filipski, A.; Kumar, S. MEGA6: Molecular Evolutionary Genetics Analysis Version 6.0. Mol. Biol. Evol. 2013, 30, 2725-2729. [CrossRef] [PubMed]

67. Pritchard, J.K.; Stephens, M.; Donnelly, P. Inference of population structure using multilocus genotype data. Genetics 2000, 155, 945-959. [PubMed]

68. Hubisz, M.; Falush, D.; Stephens, M.; Pritchard, J. Inferring weak population structure with the assistance of sample group information. Mol. Ecol. Resour. 2009, 9, 1322-1332. [CrossRef] [PubMed]

69. Falush, D.; Stephens, M.; Pritchard, J.K. Inference of population structure: Extensions to linked loci and correlated allele frequencies. Genetics 2003, 164, 1567-1587. [PubMed]

(C) 2016 by the authors; licensee MDPI, Basel, Switzerland. This article is an open access article distributed under the terms and conditions of the Creative Commons Attribution (CC-BY) license (http://creativecommons.org/licenses/by/4.0/). 